This is the peer reviewed version of the following article: Maya, J. , Jiménez, L. , Lorence, B. , Moral, G. and Hidalgo, V. (2019), Scene-Based Psychodramatic Family Therapy With Troubled Adolescents and Parents: A Pilot Study. Fam. Proc., which has been published in final form at https://doi.org/10.1111/famp.12401. This article may be used for non-commercial purposes in accordance with Wiley Terms and Conditions for Use of Self-Archived Versions. 


\section{Scene-Based Psychodramatic Family Therapy with troubled adolescents and parents. A pilot study}

Scene-Based Psychodramatic Family Therapy (SB-PFT) is an innovative treatment used with troubled adolescents and their parents to improve family relationships and reduce adolescents' problematic behavior. It integrates the principles of family therapy, psychodrama and multiple-family group methodology. This research is a pilot study to obtain empirical evidence on the SB-PFT therapeutic process by gauging the perception of change of troubled adolescents and their parents, and assess the perceived helpfulness of its methodology and techniques. Ten multiple-family intervention groups were drawn up, with 110 participants (63 adolescents and 47 parents), and we adopted a qualitative methodology with focus groups, using an inductive analysis of 290 active constructions of participant narratives. Concerning perception of change, the adolescents reported mainly gaining in social support, prosocial attitudes, keys to problem solving and expression of emotions due to the treatment. The parents perceived improvement in social support, keys for educational practices, emotional well-being and expression of emotions due to the treatment. Regarding the perceived helpfulness of methodology and techniques, both adolescents and parents highlighted the usefulness of the group methodology for gaining social support, relativizing the problem and expressing emotions. Additionally, participants referred to role-playing and mirror techniques as the most useful. In conclusion, this first study on SB-PFT presents and describes its treatment for troubled adolescents and their parents. The participants' positive perception of their personal and relational change after treatment should serve to promote further studies with quantitative methodology in order to verify the effectiveness of SB-PFT treatment. 
Keywords: family therapy; psychodrama; troubled adolescents; qualitative methodology.

Troubled adolescents are characterized to a great extent by manifesting problematic behaviors in the family and social context such as oppositional behavior, fighting, lying, physical or verbal aggression towards parents and peers, episodes of absenteeism or expulsions from school and other behaviors that may involve being included in the criminal justice system (Alexander, Waldron, Robbins, \& Neeb, 2013; Sexton, 2011). The relationship between adolescent psychosocial adjustment and the family context is widely supported by studies of adolescent development (BámacaColbert et al., 2017; Greenberg \& Lippold, 2013). Thus, the family is one of the social systems in which adolescents maintain crucial interactions (Hunger et al., 2017). The family system provides a framework of belonging which attends to the needs, establishes links of trust and promotes autonomy (Hunger et al., 2017). Additionally, there is also empirical evidence linking problematic behaviors during adolescence to a hostile and conflictive relationship with parents (Fosco, Lippold, \& Feinberg, 2014). Accordingly, while treatments focusing on symptoms may initially reduce the problem behavior, if there is no intervention in the family context and relationships, the problem behaviors will re-surface (Sexton et al., 2011). Problematic behaviors are just the visible symptom that the family system and the adolescent are in crisis. Consequently, individual change partly depends on changes in other family members, as all the system contributes and is affected by the problem situation (Patterson, 2014).

Family therapy has been highlighted as a useful strategy for intervening with the family as a system when adolescents exhibit problematic behaviors (Greenberg \& Lippold, 2013). Nevertheless, with the exception of Multisystemic Therapy (Henggeler, Schoenwald, Bordin, Rowland, \& Cunningham, 2009), and Functional Family Therapy 
(Sexton, 2011), there are as yet relatively few evidence-based treatments for intervening with adolescents with problematic behaviors and their parents. This would explain the current interest in developing treatments that increase the resources of professionals for intervening with troubled adolescents and their parents, and in recent years we have seen the emergence of new treatments partially derived from family therapy. These include Family Constellations (FC; Cohen, 2006) which highlight interest in having evidence-based treatment to improve family interactions (Sexton et al., 2011). Spain has seen the development of Scene-based Psychodramatic Family Therapy (SB-PFT). This treatment has been positively evaluated by professionals working with adolescents with problematic behaviors and their parents (Lorence et al., 2018). SB-PFT is a novel treatment respecting family therapy principles that innovates in comparison to other systemic approaches with troubled adolescents by adopting a multiple-family group format, as well as by helping the adolescents and their parents to experience conflict situations and assimilate other ways of resolving conflicts through psychodramatic techniques.

\section{Scene-Based Psychodramatic Family Therapy (SB-PFT)}

SB-PFT is a specific therapeutic treatment that aims to improve family relationships and reduce adolescents' problematic behavior (Lorence, Díaz, \& Maya, 2018; Gutiérrez, 2015). SB-PFT integrates the principles and techniques of systemic family therapy and the psychodramatic model using a group methodology, specifically multiple-family groups. SB-PFT includes assumptions derived from systemic family therapy, such as the importance of involving all the family members in the therapy, focusing on dysfunctional family relationships, understanding behavioral and emotional symptoms as part of the deterioration of family relations, and taking into account the perception, resources, and solutions proposed by the members of the family system 
(Minuchin \& Fishman, 1981). SB-PFT draws on the strengths of the participants in order to enhance individual and family change (Lorence, et al., 2018). According to the psychodramatic approach, SB-PFT is based on the importance of the action and interpersonal roles (Moreno, 1946). SB-PFT places special emphasis on the development of appropriate interpersonal roles, that is, on the different behaviors, cognitions and emotions that appear in the interaction with other people in different contexts (for example, in the adolescent, his role as a child, as a friend, his role in front of authority, etcetera). Thus, role training based on the acquisition of behavioral and emotional strategies adapted to individual and family needs (negotiation, emotional understanding, expression of emotions, etcetera) is meant to facilitate the management of different conflict situations (Blatner, 2007). In fact, Moreno (1946) believed that interpersonal roles should be trained through action as a way of improving the personal and social well-being of individuals. Specifically, SB-PFT focuses primarily on parentadolescent interaction so that adolescents can train their role according to family and social norms, and parents can train their parenting role according to adolescents' needs (Lorence et al., 2018).

SB-PFT uses the multiple-family group methodology that consists of therapeutically attending to several family systems conjointly (Keiley, ZarembaMorgan, Datubo-Brown, Pyle, \& Cox, 2015). The empirical data available for this methodology reveals that multiple-family groups favor intra-family communication and empathy (Keiley et al., 2015), problem solving (Keiley et al., 2015; Oruche, Draucker, Alkhattab, Knopf, \& Mazurcyk, 2014), relativization of the problem (Oruche et al., 2014), and a reduction in adolescents' problematic behavior (Keiley et al., 2015).

Additionally, SB-PFT considers group therapeutic factors proposed by Yalom and Leszcz (2005), among which we highlight the catharsis of the participants in the 
group, the possibility of meeting other people with the same problem, gaining insight into the reason for their behaviors and emotions, interpersonal learning among the members of the group, or the possibility of correcting negative family dynamics through the help of the other members.

SB-PFT uses five main psychodramatic techniques: role-playing, role reversal, mirror, doubling and interpolation of resistances (Cruz, Sales, Alves, \& Moita, 2018; Kipper \& Ritchie, 2003; Moreno, 1946). Role-playing consists of the dramatization of the participants with the professional auxiliary ego in some interpersonal conflicts. Role reversal is similar to role-playing, although the protagonist assumes the role of the other party in the conflict during the dramatization with the aim of changing his or her point of view and gaining a better understanding of the other party. In the mirror technique, the protagonist does not dramatize the conflict. Another participant or the auxiliary ego assumes its role in dramatization. In this way, the protagonist is made aware of his or her actions from the outside. In the doubling technique, it is the professional auxiliary ego who gives voice to the participant's feelings and thoughts when the protagonist is unable to express him or herself. Finally, interpolation of resistances consists of changing the conflict situation during dramatization to find out how the protagonist will act if the situation changes. In SB-PFT, conflict variation is characterized by the director giving the auxiliary ego an indication to express more emotions during roleplay. In addition to the psychodramatic techniques, SB-PFT introduces a new technique in the therapeutic process: the scene. This technique is used at the beginning of the session and consists of the dramatization of a family conflict only by the expert auxiliary ego (Gutiérrez, 2015).

\section{Change mechanisms}


The study of mechanisms of change is crucial in any rigorous assessment and it enables us to understand the process of personal transformation which occurs in participants during treatment (Sexton et al., 2011). SB-PFT attempts to achieve a process of change on the basis of principles of family therapy and psychodrama. From the systemic perspective, family changes such as improvement in parent-child communication, individual changes in the family context such as development of empathy, the expression of emotions or reduction of harsh parenting, are seen to act as mediators towards achieving a better family relationship and a reduction in the problem behavior (Alexander et al., 2013; Sexton et al., 2011).

According to the psychodramatic approach, the process of change includes the catharsis of the participants by following sequential aspects: people's self-appraisal and evaluation of their relationships, the revelation and expression of their emotions, and the final integration of their thoughts and emotions (Kellermann, 1984). This last point involves the identification and differentiation of the emotions, learning new coping strategies, knowledge of interpersonal relationships, and gaining emotional well-being.

\section{Present study}

This paper presents the first study of SB-PFT. Specifically, we present the main characteristics of the treatment and a set of data collected from the experiences of the participants which we hope will encourage subsequent studies and ultimately a rigorous evaluation of SB-PFT. Currently, there is a growing tendency to use the qualitative perspective, both as a complement of the quantitative perspective and exclusively. This methodology provides a detailed picture about perceptions, opinions, and feelings of different participants (Patton, 2002). 
Specifically, we set the following concrete objectives: a) gauge the perception of change of troubled adolescents and their parents; and b) examine the helpfulness of SBPFT methodology and techniques for participants.

\section{Method}

\section{Study design}

This study is based on a qualitative approach with focus groups in order to obtain a more accurate knowledge of SB-PFT from the content expressed by the participants. SB-PFT constitutes a novel treatment, although widely implemented in Spain, that is beginning to arouse scientific interest (Lorence et al., 2018). In this framework, this study design allows us to discover concepts and provide a theoretical view of data starting from the assumptions of Grounded Theory (Strauss \& Corbin, 1998), giving priority to participants' discourse over researchers' previous knowledge. For this purpose, a set of analytical guidelines from Grounded Theory have been followed to generate inductive results regarding perceived changes and helpfulness of SB-PFT methodology and techniques through a comparative data analysis process (Charmaz, 2005; Strauss \& Corbin, 1998).

This study constitutes the first step in a larger research project aimed at describing and assessing the effectiveness of Scene-Based Psychodramatic Family Therapy (SB-PFT) run by Child Welfare Services (CWS) in priority areas of southern Spain. These areas are characterized by a variety of risk factors such as socioeconomic (e.g., low income or low educational level), contextual risks (e.g., truancy, high violence in the neighborhood) and psychological factors associated with parental functioning such as parental stress (Cyr, Euser, Bakermans, \& van Ijzendoorn, 2010). CWS are public services in priority areas aimed at reducing problematic family situations; their 
field of intervention includes environmental changes such as modification of family functioning (Jonson-Reid, 2004).

CWS practitioners referred families recently enrolled in CWS (previous two years) for the SB-PFT treatment, if they met the following criteria: (a) families with troubled adolescents between 11 and 18 years exhibiting problematic behaviors such as frequent fights with peers, alcohol use, social conflicts or expulsions from school; (b) significant impairment of family relations; (c) consent for treatment from both adolescent and parents. CWS practitioners assessed problematic behavior through physical and verbal aggressiveness, anger and hostility (Buss \& Perry, 1992). Inadequate family dynamics and the use of dysfunctional educational practices defined the deterioration of family relationships (Lorber, Xu, Smith, Bulling, \& O'Leary, 2014; Olson, Portner, \& Lavee, 1985).

\section{The SB-PFT treatment}

SB-PFT developers recommend an average of 10 weekly multiple-family group treatment sessions, each one lasting two hours (Lorece et al., 2018). Two systemic therapists (directors) and two professional auxiliary egos with expertise in psychodramatic techniques lead each multiple-family group (Lorence et., 2018). The therapists who lead the multiple-family group are psychologists and have training in systemic family therapy and psychodrama accredited by official entities. The auxiliary egos may be qualified psychologists, social workers or social educators. The auxiliary egos are trained in SB-PFT by treatment therapists. This training one year prior to the application of the treatment has the objective of preparing the auxiliary egos in the use of psychodramatic techniques.

SB-PFT intervenes in parent-adolescent conflicts which are having a negative influence on family dynamics. Each SB-PFT session runs through five phases: initial 
assessment, intragroup phase, intermediate assessment, intergroup phase and final assessment. Figure 1 presents a structured session model of SB-PFT.

\section{INSERT FIGURE 1 HERE}

Initial assessment. Before the practical sessions, the practitioners responsible for the treatment (therapists and auxiliary egos) meet to agree on the objectives of the session and the opening scene which generally represents a parent/adolescent conflict, although it can also take the form of expression of thoughts, emotional expression, ambiguous scenes, and etcetera.

Intragroup phase. In this phase, the multiple-family group is divided into the adolescent group and the parent group. This phase lasts about one hour, and the aim is to achieve the catharsis of the participants (adolescents and parents) separately and produce a message to be communicated to the other group. There are six different moments: 1. Scene: the auxiliary ego acts out the selected scene; 2. Group discussion: discussion aimed at getting participants to express their opinions, feelings and experiences regarding the content of the dramatized scene; 3 . Selection of the protagonist / theme: the therapist supported by the auxiliary ego select the protagonist. The protagonist can be chosen from among the members of the group based on the following criteria: a) the participant who has shown most enthusiasm or emotional impact after commenting on the scene; b) a participant who has not been the protagonist in previous sessions; c) a participant with influence in the group and whose specific problems coincide with those of the rest and therefore, is a good model to be a protagonist of the dramatization. Sometimes, the therapist prefers to choose a main theme so that several participants can dramatize a particular conflict situation; 4 . Dramatization: the aim here is for the protagonist to reach catharsis through psychodramatic techniques (role-playing, role reversal, mirror, doubling or interpolation 
of resistance); 5. Integration and sharing: in this stage people comment on what happened during the dramatization so that the protagonist can integrate the emotions experienced during the dramatization; 6 . Choice of message: the group draws up a message to be given to the other group. This message can be from the protagonist to the other members of his or her family system or a group message. The message chosen may be a statement, a question, a conclusion or a scene to be acted out in front of the other group for them to discuss.

Intermediate assessment. There is a five-minute break in which the therapists and auxiliary egos from each group meet to relay the events that have occurred in each group so far and select the message to be transmitted to each group. They must decide whether it is the message that the adolescent group wants to transmit or the message that the parents want to transmit to the adolescents or both messages.

Intergroup phase. The two groups meet bringing together the different family systems adopting a multiple-family group methodology, under the co-direction of all the practitioners involved. The intergroup phase follows a similar routine to the intragroup one, although the focus of treatment is on family systems. At this final moment, the therapists provide feedback to the group which favors the process of integration of the emotions experienced during the session.

Final assessment. Practitioners meet to exchange information and assess the session. They assess the evolution of the group as a social system, and the evolution of each family system and its members. They conclude by identifying possible areas and contents for future interventions.

One of the implications of SB-PFT is the co-direction of the groups by the therapist and auxiliary ego. In general terms, the therapist must generate the therapeutic alliance with the group and take the main decisions during the therapeutic process 
(Blatner, 2007). In SB-PFT, the therapist observes the interactions within the group, formulates therapeutic hypotheses within the framework of systemic theory and tests these hypotheses by proposing different dramatizations with the technical resources (role reversal, doubling, and etcetera) that the auxiliary must execute.

The auxiliary ego has to support, deliver and execute the therapist's decisions. In this case, the auxiliary ego plays an important role during the sub-phase of dramatization because he/she is responsible for performing the dramatizations (roleplaying, role reversal, etcetera), which have previously been decided by the therapist (Moreno, 1978). Specifically, during the dramatization (the moment when participants must reach catharsis) the auxiliary ego interacts directly with the participants, while the director observes the dramatization from outside giving instructions and orders to the auxiliary ego to modify the existing interactions in order to mobilize participants' resources in conflictive situations.

\section{Participants}

This study included all the families which received SB-PFT in 2016.

Specifically, 10 multiple-family intervention groups were drawn up, involving at least one adolescent and one parent from each family. As suggested by SB-PFT developers, 10 treatment sessions were performed with each multiple-family intervention group. The multiple-family groups ranged in size from 8 to 22 participants. The flow of cases through the trial is shown in Figure 2. Participants were classified as dropouts if they did not attend a minimum of three treatment sessions and the dropout rate was $31.67 \%$. In total, 161 participants were enrolled in SB-PFT. From those, 110 participants (63 adolescents and 47 parents) completed the treatment and participated in the last session (focus groups). $69.09 \%$ of completers attended more than 6 treatment sessions; 8 sessions represented the modal number of sessions. 


\section{INSERT FIGURE 2 HERE}

The adolescents' ages ranged from 11 to $18(M=14.20 ; S D=1.47)$, with a balanced distribution of sex (53.97\% girls). The parents' ages ranged from 29 to 54 ( $M$ $=42.36 ; S D=6.23)$. In most cases $(72.34 \%)$ the mother was the participant $(21.28 \%$ the father, and $4.25 \%$ the parent's partner); and they had low-medium educational levels (14.89\% incomplete compulsory schooling, $34.04 \%$ with primary studies and $23.40 \%$ with secondary studies). As for types of family, $36.17 \%$ were single-parent, $38.29 \%$ intact two-parent and $25.53 \%$ reconstituted families. Families consisted of approximately four members, with an average of two children. Of these, $95.45 \%$ were of Spanish origin; $2.72 \%$ were Colombian immigrants and $1.82 \%$ Moroccan immigrants.

The main stressful life events experienced over the previous five years by these families, as reported by the adolescents, were: major financial difficulties in the family (54.0\%); important arguments between the parents (50.8\%), serious problems of adolescents or parents with the justice system (31.7\%); a close relative's problems with drugs or alcohol (25.4\%); conflictive relations between the adolescent and his/her partner (22.2\%); intra-family abuse towards the adolescent $(20.6 \%)$.

\section{Procedure}

In the last session, each multiple-family group was divided into the adolescent group and the parent group to conduct the focus groups and to explore the changes perceived by adolescents and parents. Sixteen focus group meetings were held in total. These groups met to promote interactions among the participants, obtain different points of view, analyze agreements and disagreements, and foster the onset of emerging contents (Barbour \& Kitzinger, 1999). The size of the focus groups ranged from 4 to 13 
people. Two members of the research team trained in this methodology chaired the focus groups, who had also participated as observers throughout the treatment.

The study researchers drew up the script to be discussed by the groups, and it was structured around two main themes: perception of change of the participants and perceived helpfulness of the methodology and techniques. The perception of change was evaluated by the following questions: "What has changed as a result of attending the sessions?" "What changes have you perceived in your parents/child after the intervention?" and "What is the best thing you take home from your participation?" We evaluated the usefulness of the SB-PFT methodology and the techniques through the following questions: "How has this group methodology helped you?" and "What do you think about dramatizations and other techniques used in these sessions?" The focus groups lasted from 30 to 40 minutes. We made audio recordings of all the groups.

Every informant participated in the study voluntarily, after signing an informed consent form in accordance with the Declaration of Helsinki. Researchers explained the aims of the project and assured participants their anonymity would be protected. Ethics approval was obtained from the University responsible for the study.

\section{Data Analysis}

The coordinators of each focus group transcribed the participants' discourse for processing and coding with the qualitative data analysis software ATLAS.ti 7.0. We followed the assumptions of the Grounded Theory proposed by Strauss and Corbin (1998). Firstly, we performed a process of open coding by identifying and defining significant fragments of the participants' discourse. The first analysis decision was to specify the interventions that were susceptible of analysis. For this purpose, the research team discarded the interventions that did not represent an elaboration of the discourse, such as "yes", "no", "me too" in order to eliminate possible cases of analysis 
doubling. The significant fragments of analysis were named active constructions of the narrative. This analysis began by coding the narrative inductively, openly, and without preset theoretical assumptions, thus carrying out a process of live coding, line by line. From this process, a list of codes emerged, that prioritized the participants' own expressions and words.

Subsequently, we carried out an axial coding, grouping the codes into categories. To elaborate these analytical categories, we took into account the possible groupings and differentiations of the codes in central and peripheral themes, their frequency of occurrence, the properties of the created categories, the merging of categories, and the elimination of redundant categories. As Braun and Clarke (2006) made clear, this is a flexible process of analysis, going back and forth, quite unlike linear sequentially. Additionally, the researchers formed two groups to reach an agreement about the final outcome and ensure the thoroughness of the study (Creswell, 2007). The researchers reached full agreement about the codes after three in-depth reviews of the data.

\section{Quality and validity}

In order to achieve an adequate level of rigor, validity, and credibility in the qualitative analysis of the data (Patton, 2002; Tracy, 2010), we adopted the following methods: (a) inter-data triangulation or constant comparative method (Strauss \& Corbin, 1998) involving the systematic comparison of codes and their properties stemming from the analysis of the data in different fragments of the same material, among different materials, participants, situations and at different times to search for regularities or patterns to allow us to define a category or relation; (b) theoretical saturation to validate that no new significant properties and dimensions had emerged from the analysis of the participants' narrations, leading to new categories (Patton, 2002); (c) triangulation or 
process of validation from different sources, facilitating the emergence of categories shared by different informants; in this study, through the comparison of categories of similar or different content between adolescents and parents (Creswell, 2007); (d) peer review or inter-analytic triangulation (Creswell, 2007), contrasting the results of each researcher's coding, analyzing in greater detail those in which agreement was not reached; (e) intra-evaluator reliability (Miles \& Huberman, 1994); this procedure required each researcher, roughly two-thirds of the material analyzed, to start again and re-examine the codes; (f) consideration of outliers, that is, the analysis of data that pointed in the opposite direction of the general structure (Mays \& Pope, 2000); (g) a multi-informant method through focus groups (Mays \& Pope, 2000).

\section{Results}

Due to space constraints and the large size of the tables, all of the tables are annexed as Supporting Information. They show examples of the discourse of participants in each category that emerged from the qualitative analysis.

\section{Perception of change}

The in-depth analysis of the participants' discourse revealed the changes perceived by the participants, identifying 290 active constructions of narratives that reflected some kind of change. On the basis of the contents, we grouped these narratives into 23 categories or contents of change.

Table S1 presents the contents of change identified by the adolescents, their frequency of occurrence and an example from each category. We identified 13 contents of change in adolescents. Adolescents manifested that thanks to SB-PFT they had perceived an increase in their social support network, a change in their attitudes which led to improved family and social adjustment, and new keys to problem solving. Other changes that adolescents mentioned frequently were a greater facility for expressing 
their emotions and feelings, better communication with their parents, increased emotional wellbeing or a reduction in their aggressive behaviors.

Table S1 also shows the changes that parents perceived in their children. Parents agreed with their children in 7 out of the 13 categories. For the parents, the most important changes in the adolescents in SB-PFT were related to greater expression of emotion and feelings, a change in attitude which involved greater acceptance of family and social norms, new keys to problem solving and improved emotional wellbeing. The parents' discourse also identified four contents of change which the troubled adolescents had not mentioned. Of these, parents highlighted greater control of adolescents' impulsive behavior, greater empathy and an increased awareness of why their parents behaved and thought as they did.

Table S2 presents the categories identified by the parents, the frequency of occurrence and an example of each content. The parents identified 11 contents of change in this pilot study. The active constructions of parents' narrative indicated mainly an increase in their social support network after SB-PFT, new understandings of educational practices, greater expression of their emotions and feelings and improved social wellbeing characterized by a greater presence of feelings of peace and calm. Other contents included better communication with their children, more self-awareness regarding their own and their children's behaviors, thoughts and motivations, and a greater perception of self-control. Table S2 is completed with the changes that the adolescents perceived in their parents. Here adolescents and parents coincided in only 4 out of the 11 categories. The adolescents revealed that after SB-PFT their parents had a greater understanding of their children's behaviors and thinking, and showed greater empathy. Furthermore, the adolescents informed about changes in their parents that the latter had not mentioned. Specifically, the adolescents pointed out that their parents 
showed less over-reactivity, more signs of affection and greater promotion of their children's autonomy.

A synthesis of the changes that have emerged in adolescents and parents is presented in Figure 3.

\section{INSERT FIGURE 3 HERE}

Finally, it should be noted that the number of narratives that showed absence of changes in adolescents and parents was negligible in comparison with the presence of perceived changes. Only 3 of the parents' narratives and 9 of the adolescents' narratives reflected absence of changes.

\section{Perceived helpfulness of methodology and techniques}

Table S3 shows the methodological and technical aspects which were perceived as helpful by the adolescents and their parents, the frequency of occurrence and an example of the narrative. Thus, in their discourse adolescents referred mainly to the helpfulness of the group methodology as a facilitator of social support and expression of emotions. Furthermore, the adolescents reported that the group nature of SB-PFT introduced them to other adolescents in their same situation. Likewise, the main techniques reported as helpful by adolescents during the therapeutic process were roleplaying, the mirror and interpolation of resistance. Adolescents reported that these techniques helped them acquire new strategies for resolving conflicts, express their emotions and feelings, perceive peer support, reflect on their situation and improve selfknowledge of their thoughts, behaviors and emotions.

Finally, the parents revealed that the group methodology allowed them to meet others in the same situation, acquire understanding of educational practices, express emotions and form a new social support network. Likewise, the parents highlighted the importance of group cohesion and trust to encourage them to open up emotionally. 
Role-playing and mirror techniques had the most references in the parents' discourse analysis and they stated that these two techniques had helped them to improve their educational strategies, express emotions and improve their self-knowledge about their thoughts, behaviors and emotions. The parents also referred to the scene as one of the main techniques in SB-PFT which facilitated the development of empathy and a greater understanding of their children.

\section{Discussion}

This study has presented, for the first time, the theoretical and methodological principles of SB-PFT, implemented with adolescents with problematic behaviors and their parents in priority areas. It has included an extensive and detailed account of the treatment to facilitate its reproduction in future applications. The presentation of SBPFT contributes to the search for intervention and treatment resources for a specific population - problematic adolescents and their parents - which requires therapeutic intervention (Sexton, 2011). The study results are discussed using a qualitative and multi-informant methodology to facilitate understanding of the contents manifested by adolescents and their parents (Tracy, 2010). These contents, analyzed inductively through the open and axial coding of Grounded Theory, allow us to respond to the objectives of the study and obtain a series of theoretical implications for future evaluations of SB-PFT.

The first study objective was to analyze the changes perceived as a result of the SB-PFT. Participants referred to changes in parent-child interactions (such as better intrafamily communication), individual changes in adolescents (such as the appearance of more prosocial and less conflictive behaviors), individual aspects of the parents (such as better expression of emotions and improved self-knowledge), and changes in the support network. Perception of change on different levels is important in these 
treatments intervening in the family system. In fact, Sexton et al. (2011) anticipated that it was important to achieve relational changes to prevent problematic behaviors from reappearing in adolescents.

Regarding relational changes, one of the objectives of SB-PFT is to improve family relations by modifying dysfunctional relations between adolescents and their parents. In family therapy (Minuchin \& Fishman, 1981) one of the elements which changes parent-adolescent interactions is the use of educational practices better suited to the needs of the adolescent. In SB-PFT, parents revealed that they had modified their ideas about educational practices, highlighting the importance of using less coercive strategies, while the adolescents pointed to specific aspects of their parents' educational practice which had changed, such as the use of less reactive practices. Furthermore, according to systemic family therapy (Minuchin \& Fishman, 1981), another important element revealed by both parents and adolescents, and which therefore seems to be a direct consequence of the SB-PFT, was the improvement in communication between them. In general, parents and adolescents revealed changes in parent-adolescent interactions such as greater attention to the needs of the other family member, and the promotion of autonomy that corresponds to the functions of the family as a social system (Hunger et al., 2017). The fact that parents and adolescents refer to improvements in family relations and changes in the other member of the family system has to be positive for adolescent development and the family climate (Bámaca-Colbert et al., 2017; Hunger et al., 2017).

In relation to the personal changes revealed by the adolescents, we found changes in problems of either a behavioral, cognitive or emotional nature. The fact that the adolescents were the reason for which the families were referred to SB-PFT due to their problematic behaviors underlines the importance of the active constructions of the 
adolescents referring to a decrease in physical or verbal aggressiveness, and mainly the development of prosocial attitudes, such as acceptance of family, social and school rules. Thus, adolescents' discourse on this point would seem to be consistent with the objectives of the treatment directly related to reducing problematic behaviors. Adolescents also referred to cognitive changes such as greater knowledge about the keys to problem solving and deeper self-knowledge. These results are consistent with other treatments for families with troubled adolescents (Robbins, Alexander, Turner, \& Hollimon, 2016; Sexton, 2011), apart from the result referring to an improvement in self-knowledge, which has not been reported before. Finally, the adolescents revealed improvements in their emotional skills such as better expression of their emotions and greater emotional wellbeing. These changes are consistent with the use of the psychodramatic techniques in SB-PFT whose objective is to facilitate the emotional liberation (Kellermann, 1984).

From systemic principles, it is clear that changes in the adolescent partly depend on changes in the other family members and all the system contributes to, and is affected by, the problem situation (Patterson, 2014). Hence, this study analyzed the changes perceived by the parents. Besides changes in their educational practices, the parents revealed other cognitive and behavioral changes which were not initially foreseen in the objectives of SB-PFT. Parents reported greater self-knowledge and more coping strategies for the problems of daily life. At an emotional level, parents reported better expression of emotions and improved emotional wellbeing, changes possibly facilitated by the psychodramatic orientation of SB-PFT (Moreno, 1946).

Finally, adolescents and parents coincided in mentioning improvements in perceived social support. Encouraging sources and resources of social support in the lives of these families should be highlighted as one of the great strengths of this 
treatment. This result is not just remarkable for being the one referred to most by the participants, but also for the confirmed benefits of social support for personal wellbeing, family relations and coping with stress (Cohen, 2004).

The second objective was to provide evidence of the perceived helpfulness of the methodology and techniques used in SB-PFT by troubled adolescents and parents. They coincided in highlighting the importance of the group methodology for promoting social support. Thus, one of the novel features of SB-PFT with respect to other treatments with adolescents with problematic behaviors is the use of multiple-family groups, the main implication of which is the generation of support networks. This result is consistent with the group therapeutic factors proposed by Yalom and Leszcz (2005). In accordance with these authors, the participants revealed how the group and the confidence reached between the families and the adolescents had enabled them to meet other families with the same problem, express their emotions and facilitate interpersonal learning among the members of the group. These results tie in with those reported in interventions using multiple-family groups (Oruche et al., 2014).

As for the techniques used in SB-PFT, both adolescents and parents highlighted the value of role-playing and the mirror. Coinciding with the opinion of psychodramatic experts (Cruz et al., 2018; Moreno, 1946), adolescents and parents underlined the importance of role-playing for expressing emotions, improving self-knowledge, improving the keys for educational practices and perceived support in the representation of conflictive situations. Role-playing facilitates the step from discourse to action and the cathartic process in the participants (Kellermann, 1984; Moreno, 1946). Together with role-playing, the participants valued the helpfulness of the mirror technique consisting of the dramatization of a situation in which the protagonist stays out of the dramatization and his or her role is played by the auxiliary ego or other member of the 
group (Cruz et al., 2018). This recent study highlighted the importance of the mirror for making protagonists become aware of their behaviors. In our study, both adolescents and parents made references in their discourses to this technique as a facilitator of the acquisition of keys to problem solving, for promoting reflection, improving selfknowledge and the perception of feeling support. In turn, the scene (Gutiérrez, 2015) is a new technique proposed by SB-PFT for opening the treatment sessions. It was referred to more by parents than by adolescents as a technique favoring empathy and knowledge about other family members, although it was not referred to as much as roleplaying or the mirror. Finally, in contrast to the study by Kipper and Ritchie (2003), the importance that participants attributed to techniques of role reversal and doubling was low.

Globally, the changes perceived by the participants after the SB-PFT are consistent with the objectives of the treatment. Indeed, that both the adolescents and their parents perceived relational and individual changes ties in with the framework of SB-PFT's systemic theoretical approach. Therefore, as a theoretical implication stemming from our inductive analysis (see Figure 3), we found that the changes perceived at different levels (parent-adolescent interaction; individual in the adolescent and in the parent; and the development of social support) should serve as a guide for developing empirical understanding about the effects of this treatment. In addition, in an area where deductive studies prevailed, the qualitative analysis on the helpfulness of psychodramatic techniques has increased understanding on a theme with few scientific contributions from an inductive point of view (Cruz et al., 2018). Therefore, participants' references to the utility of techniques such as role-playing and the mirror, and the benefits mentioned of the group methodology give us a positive vision of the SB-PFT, which is highly gratifying for the problematic adolescents and their parents. 


\section{Limitations and future research}

There were several limitations in this study that should be considered when interpreting the findings. At the methodological level, there may have been drawbacks with the focus groups such as the influence that some participants may have exerted over the rest of the group. Additionally, the questions selected may have influenced the participants and served as guidelines for participants to report positive changes to satisfy researchers' expectations. Likewise, the questions may have hindered the generation of relationships and a final theory that link the contents of perceived changes and the perceived benefit of the methodology and techniques of the SB-PFT. Furthermore, we had to perform three reviews of the data before reaching consensus ratings due to differing levels of knowledge of the coding process amongst researchers. Hence, the results should be treated with caution and need to be contrasted at a later stage with quantitative approaches following quality standards in programme evaluation (Flay et al., 2005). Additionally, it would have been interesting to explore the components of treatments that did not help. At the theoretical level, we must bear in mind that troubled adolescents are not a homogeneous population (Sexton, 2011) and therefore the individual differences must be taken into account in the study design.

As for improvements for future studies, we propose that the results presented in this paper must be complemented by other studies to evaluate SB-PFT exhaustively with a multi-method design completing the collection and analysis of data with quantitative procedures in a randomized controlled trial. It would also be interesting to conduct more studies to be able to generalize the results obtained, establish an integration and explanation of the SB-PFT change model and study the role of possible intervention moderators. The incorporation of all these improvements would allow compliance with all the principle quality criteria for evidence-based procedures (Flay et 
al., 2005). As for ways of improving SB-PFT, we make three suggestions: a) promote intervention components to encourage the development of empathy amongst the adolescents; b) train parents in new educational practices; c) enhance the use of the techniques of role reversal, doubling and the scene so they are perceived as more helpful by participants; and d) develop strategies during the therapeutic process to make participants aware of their personal strengths.

\section{Conclusions}

Despite the aforementioned limitations, the use of an inductive and open methodology to analyze the participants' discourse revealed a wide range of perceived changes. The resulting contents will delimit the dimensions that must be evaluated in quantitative studies. Hence, this work, supported by the assumptions of Grounded Theory, has generated the first empirical findings about SB-PFT. Furthermore, this study has presented the theoretical and methodological framework of the SB-PFT. Additionally, the structure of the SB-PFT sessions and techniques have been described to encourage replication by other professionals. In conclusion, this study should help understanding of the therapeutic process behind SB-PFT and serve as a first step towards improving the intervention and research of SB-PFT with adolescents with problematic behaviors and their parents.

\section{References}

Alexander, J.F., Waldron, H.B., Robbins, M.S., \& Neeb, A.A. (2013). Functional family therapy for adolescent behavior problems. Washington, DC: American Association.

Bámaca-Colbert, M.Y. Gonzales-Backen, M. Henry, C.S., Kin, P.S.Y., Roblyer, M.Z., Plunkett, S.W., \& Sands, T. (2017). Family profiles of cohesion and parenting 
practices and Latino Youth Adjustment. Family Process.

https://doi.org/10.1111/famp.12314

Barbour, R.S., \& Kitzinger, J. (Eds.). (1999). Developing focus group research:

Politics, theory and practice. London: Sage.

Blatner, A. (2007). The role of the meta-role: An integrative element in psychology. In C. Baim, J. Burmeister and M. Maciel (Eds.), Psychodrama: Advances in Theory and Practice (pp. 53-67). London: Routledge.

Braun, V., \& Clarke, V. (2006). Using thematic analysis in psychology. Qualitative Research in Psychology, 3(2), 77-101.

http://doi.org/10.1191/1478088706qp063oa

Buss, A.H., \& Perry, M.P. (1992). The aggression questionnaire. Journal of Personality and Social Psychology, 63(3), 452-459. http:// doi.org/10.1037/00223514.63.3.452

Charmaz, K. (2005). Grounded theory in the 21st Century. In N.K. Denzin and Y.S. Lincoln (Eds.), The Sage handbook of qualitative reserach (3rd ed., pp.507535). London: Sage Publications.

Cohen, D.B. (2006). 'Family Constellations': An innovative systemic phenomenological group process from Germany. The Family Journal, 14(3), 226-233. https://doi.org/10.1177/1066480706287279

Cohen, S. (2004). Social relationships and health. American Psychologist, 59, 676- 684. http://dx.doi.org/10.1037/0003-066X.59.8.676

Creswell, J.W. (2007). Qualitative inquiry and research design: Choosing among five traditions (2nd ed.). Thousand Oaks, CA: Sage. 
Cruz, A., Sales, C.M.D., Alves, P., \& Moita, G. (2018). The Core Techniques of Morenian Psychodrama: A systematic review of literature. Frontiers in Psychology, 9:1263. https://doi.org/10.3389/fpsyg.2018.01263

Cyr, C., Euser, E.M., Bakermans, M.J., \& van Ijzendoorn, M.H. (2010). Attachment security and disorganization in maltreating and high risk families: A series of meta-analyses. Development and Psychopathology, 22(1), 87-108. http://dx.doi.org/10.1017/S0954579409990289

Flay, B., Biglan, A., Boruch, R.F., González, F., Gottfredson, D., Kellam, S. ... Ji, P. (2005). Standards of evidence: Criteria for efficacy, effectiveness and dissemination. Prevention Science, 6(3). http://dx.doi.org/10.1007/ s11121-005$5553-y$

Fosco, G.M., Lippold, M., \& Feinberg, M.E. (2014). Interparental boundary problems, parent-adolescent hostility, and adolescent-parent hostility: A family process model for adolescent aggression problems. Couple and Family Psychology, Research and Practice, 3(3), 141-155. https://doi.org/10.1037/cfp0000025

Greenberg, M.T., \& Lippold, M.A. (2013). Promoting healthy outcomes among youth with multiple risks: innovative approaches. Annual Review of Public Health, 34(1), 253-270. https://doi.org/10.1146/annurev-publhealth-031811-124619

Gutiérrez, J.A. (2015). Intervención comunitaria desde el enfoque psicoescénico. Mosaico, 60, 86-94.

Henggeler, S., Schoenwald, S., Bordin, C., Rowland, M., \& Cunningham, P. (2009). Multisystemic therapy for antisocial behavior in children and adolescents. New York, NY: Guilford.

Hunger, C., Bornhäuser, A., Link, L., Geigges, J., Voss, A., Weinhold, J., \& Schweitzer, J. (2017). The Experience in Personal Social Systems Questionnaire 
(EXIS.pers.): Development and psychometric properties. Family Process, 56(1), 154-170. https://doi.org/ 10.1111/famp.12205.

Jonson-Reid, M. (2004). Child welfare services and delinquency: The need to know more. Child Welfare: Journal of Policy, Practice, and Program, 83(2), 157-173.

Keiley, M.K., Zaremba-Morgan, A., Datubo-Brown, C., Pyle, R., \& Cox, M. (2015). Multiple-family group intervention for incarcerated male adolescents who sexually off end and their families: Change in maladaptive emotion regulation predicts adaptive change in adolescent behaviors. Journal of Marital and Family Therapy, 41(3), 324 339. http://dx.doi.org/10.1111/jmft.12078

Kellermann, P.F. (1984). The place of catharsis in psychodrama. Journal of Group Psychotherapy, Psychodrama and Sociometry; 37(1), 1-13. Retrieved from http://peterfelix.tripod.com/home/Catharsis.pdf

Kipper, D.A., \& Ritchie, T.D. (2003). The effectiveness of psychodramatic techniques: A meta-analysis. Group Dynamics: Theory, Research and Practice, 7(1), 13-25. http://dx.doi.org/10.1037/1089-2699.7.1.13

Lorber, M.F., Xu, S., Smith, A.M., Bulling, L., \& O'Leary, S. (2014). A new look at the psychometric of the Parenting Scale through the Lens of Item Response Theory. Journal of Clinical Child and Adolescence Psychology. 43(4), 613-626. http://dx.doi.org/10.1080/15374416.2014.900717

Lorence, B., Mora, M., \& Maya, J. (2018). Description and analysis of the quality of programs for the treatment of antisocial behavior in the city of Huelva. Journal of Research in Social Pedagogy, 32, 83-95. http://dx.doi.org/10.7179/PSRI_2018.32.07

Mays, N., \& Pope, C. (2000). Assessing quality in qualitative research. British Medical Journal, 320(7226), 50-52. http:// dx.doi.org/10.1136/bmj.320.7226.50 
Miles, M.B., \& Huberman, A.M. (1994). Qualitative data analysis: An expanded sourcebook. Newbury Park, CA: Sage.

Minuchin, S., \& Fishman, H.C. (1981). Family therapy techniques. Cambridge, MA: Harvard University Press.

Moreno, J.L. (1946). Psychodrama (Vol. 1). Beacon, NY: Beacon House.

Moreno, Z.T. (1978). The Function of the Auxiliary Ego in Psychodrama with special reference to Psychotic Patients. Group Psychotherapy, Psychodrama and Sociometry, 31, 163-166.

Olson, D.H., Portner, J., \& Lavee, Y. (1985). FACES III. St Paul: University of Minnesota.

Oruche, U.M., Draucker, C., Alkhattab, H., Knopf, A., \& Mazurcyk, J. (2014). Interventions for family members of adolescents with disruptive behavior disorders. Journal of Child and Adolescent Psychiatric Nursing, 27(3), 99-108. https://doi.org/10.1111/jcap.12078

Patterson, T. (2014). A cognitive behavioral systems approach to family therapy. Journal of Family Psychotherapy, 25(2), 132-144. http://dx.doi.org/10.1080/08975353.2014.910023

Patton, M.Q. (2002). Designing qualitative studies. In M.Q. Patton (Ed.), Qualitative research and evaluation methods (3rd ed., pp. 209-257). Thousand Oaks, CA: Sage.

Robbins, M.S., Alexander, J.F., Turner, C.W., \& Hollimon, A, (2016). A evolution of Functional Family Therapy as an evidence-based practice for adolescents with disruptive behavior problems. Family Process, 55(3), 543-557. https://doi.org/10.1080/17571472.2017.1362713 
Sexton, T. (2011). Functional family therapy in clinical practice: An evidence-based treatment model for working with troubled adolescents. New York, NY: Routledge.

Sexton, T., Gordon, K.C., Gurman, A., Lebow, J., Holtzworth-Munroe, A., \& Johnson, S. (2011). Guidelines for classifying evidence-based treatments in couple and family therapy. Family Process, 50(3), 377-392. http://doi.org/10.1111/j.15455300.2011.01363.x

Strauss, A., \& Corbin, J.M. (1998). Basics of qualitative research: Grounded theory procedures and techniques (2nd ed.). Newbury Park, CA: Sage.

Tracy, S.J. (2010). Qualitative quality: eight "big-tent" criteria for excellent qualitative research. Qualitative Inquiry, 16(10), 837-851. http://dx.doi.org/10.1177/1077800410383121

Yalom, I.D., \& Leszcz, M. (2005). The theory and practice of group psychotherapy (5th ed.). New York, NY: Basic Book.

\section{SUPPORTING INFORMATION}

Additional Supporting Information may be found in the online version of this article:

Table S1. Contents of perceived change in adolescents (self-perceived and informed by others)

Table S2. Contents of perceived change in parents (self-perceived and informed by others)

Table S3. Perceived helpfulness of the methodology and techniques of SB-PFT 